\title{
Research on Enterprise Operating Strategy for Digital Library
}

\author{
Jinghui Wang ${ }^{\mathrm{a}}$, Yanyu Zang ${ }^{\mathrm{b}}$, Hao Cui ${ }^{\mathrm{c}}$, Runmeng Qin ${ }^{\mathrm{d}}$, Wei $\mathrm{Cao}^{\mathrm{e}}$ and \\ Zhiyao Huang ${ }^{\dagger}$ \\ Jilin Agricultural University, Changchun 130118, Jilin, China

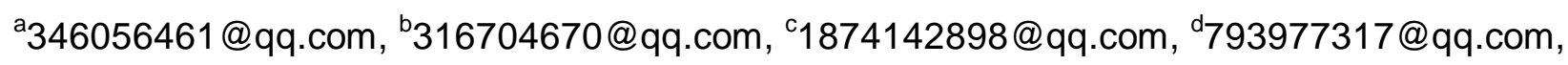 \\ e1245724166@qq.com, ${ }^{\dagger} 839175942 @ q q . c o m$
}

Keywords: Digital library; Enterprise operating; Marketing strategy

\begin{abstract}
Based on the modern market economy, and according to the characteristics of digital libraries, this paper discusses the enterprise operating strategy for digital library from four aspects which are the operating environment, company management mode, business model and marketing strategy in order to ensure social benefits and improve the operating efficiency of digital library.
\end{abstract}

\section{Introduction}

Enterprise operating of a digital library is a kind of market-oriented operation model to improve the operating efficiency of the digital library, protect intellectual property, promote information resources sharing and realize economic benefit. The core of it is to carry out the marketing operation for the assets (tangible assets and intangible assets) which constitute the digital library and establish the new system of investment of cultural undertakings which conform to the demand of market economy [1]. As a public welfare unit, digital library will meet lots of problems such as standard, model, copyright and so on in the process of the transition to the operating unit. Only when the following problems are well solved can digital libraries develop well. The construction of the digital library in our country has not yet been completely placed in the market environment, and the collection and allocation of information resources are funded by the state and managed by administrative departments [2]. Such development can't add value to the assets and it is entirely driven by external forces. However, with the rapid development of today's information society, digital libraries only rely on their own initiative development to keep them growing so that they will not disappear in the cruel market competition [3]. The enterprise operating of the digital library will be a new model and a new goal for its future development.

\section{Construction of the Enterprise Operating Environment of Digital Library}

The enterprise operating of digital libraries can not be separated from the support of the basic environment. The environment described here includes institutional environment, policy environment, market environment and human resources environment. At present, the non enterprise operating of digital library is a prominent problem in the process of its construction. The unclear property relations, the administrative allocation of resources and the unscientific management all affect the development of digital libraries. Therefore, it is necessary to change the system of digital library, reform the state-owned assets management system of digital library and establish the modern enterprise system of the digital library. The reform of the state-owned assets system of the digital library can be carried out according to the idea of "separation of the three powers" which is the separation of government and enterprise, separation of state-owned assets ownership and operation rights and separation of the assets operation rights and daily management rights. At the same time, according to the requirement of the modern enterprise system, the organization structure of three-grade management should be established in order to manage the state-owned assets of digital libraries. That is, management organization in national level-state-owned assets management institution which belongs to digital library-enterprise organizations specializing in state-owned assets. 


\section{Implementation of a Fully Corporate Management Model}

In order to implement the enterprise operating, digital library must get rid of the awkward position of the affiliated institution of the current administrative department, free from the shackle of the administration, clear the subject of property rights and subject of operation in the legal sense and implement fully corporate self-management, self-financing and self-development. Normative management structure of the enterprise legal person should be established within an enterprise to scientifically manage and effectively supervise enterprises. Right business strategy should be adopted to create greater benefits and make the digital library integrate into the society as an independent social legal person and a market competition subject. The management of digital library is different from the general companies. The profits of it are very low and also it has to bear royalty fees, therefore the full enterprise management system can make it get social benefits, that is when it shares network information resources, it can expand economic benefit and realize the system reform from management to product promotion and then to customer service integration.

Sectoral Structure and Function Design of Corporate Management. Through the deep analysis, induction and conclusion of the operating mode of digital libraries and general enterprises, the writer has designed the corporate management mode which conforms to the enterprise operating of the digital library. The department management structure is shown in Fig. 1.

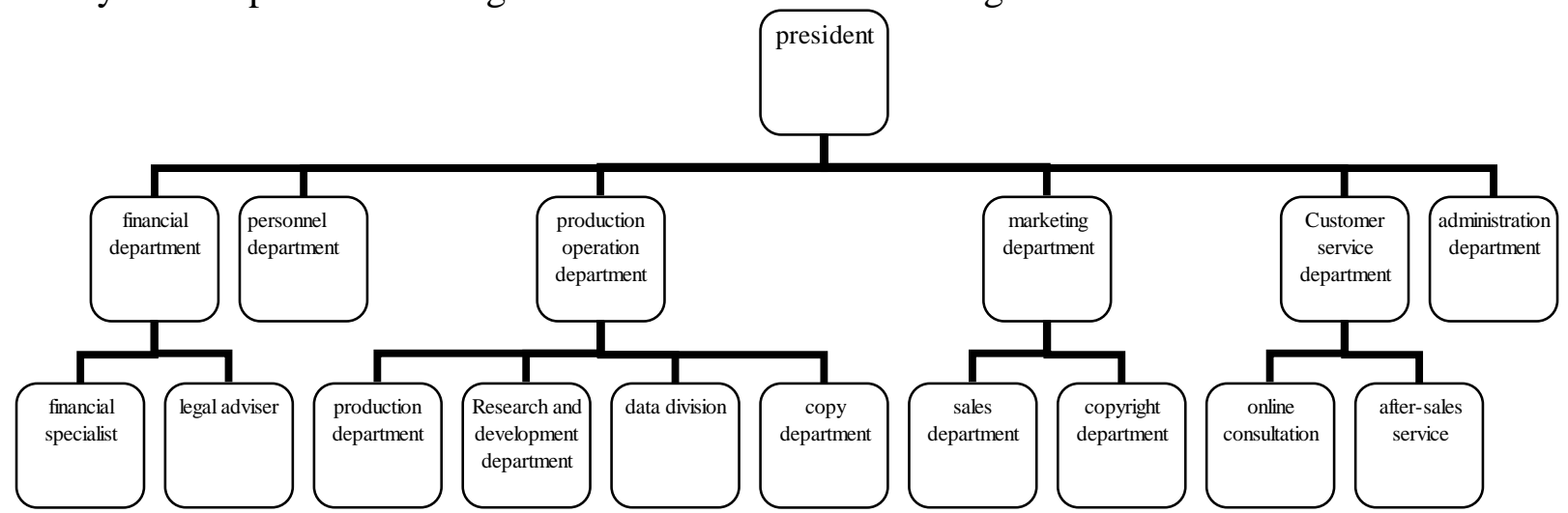

Figure 1. The corporate management structure chart of digital library

Different from the management structure of the general company, digital library has its own special departments, such as production and operation department, marketing department and customer service department, which have some special functions of a digital library.

The first one is the production and operation department. The production and operation department is divided into four departments which are production department, research and development (R\&D) department, data division and copy department. The production department is responsible for the processing of printed books at the factory. This department should input new books which are catalogued by MARC into the computer to make them become electronic books. The R\&D department is responsible for developing procedures for making printed books into electronic books, as well as procedures required by some departments of the company, and maintaining the digital library website. The data division is responsible for the processing of electronic books, so as to meet the standards of uploading to the internet and check, classify and articulate new books. The copy department is responsible for copying relevant books and videos from customers' orders and then sending them to customers.

The second one is marketing department. The sales department in the marketing department is mainly responsible for selling their own servers, selling e-books on the website and so on. The copyright department is mainly responsible for discussing copyright issues with authors and publishers, protecting the intellectual property rights of digital books and providing a large amount of information resources that can be shared to meet the users' reading needs.

The third one is the customer service department. Customer service department is mainly divided into online consultation department and after-sales service department. Online consultation department can provide online consultation service for every user who enters into digital library website and provide 
other timely services. After-sales service department mainly provides after-sales service for the servers of large client and ordered electronic books.

Design of the Cooperative Relationship among Departments. For digital library which is the enterprise with a quick update of production and technology, cooperation among departments is very important. If the cooperation is proper, the operating efficiency of the enterprise will be improved. Cooperation means that firstly all departments should have a certain understanding of the company's productions and service concept, so that they can solve problems timely. Secondly, all departments should communicate with each other, actively put forward questions in each regular meeting, discuss and get the tentative plan. Finally, they should constantly bring forth new ideas in their work fields. The innovation of digital library is very important. They should actively develop information products with high content of knowledge, realize the ordering of information resources and externalization of knowledge, increase the value of intellectual capital continuously and occupy and expand information market by using innovative products. The cooperation relationship of every department is shown in Fig. 2.

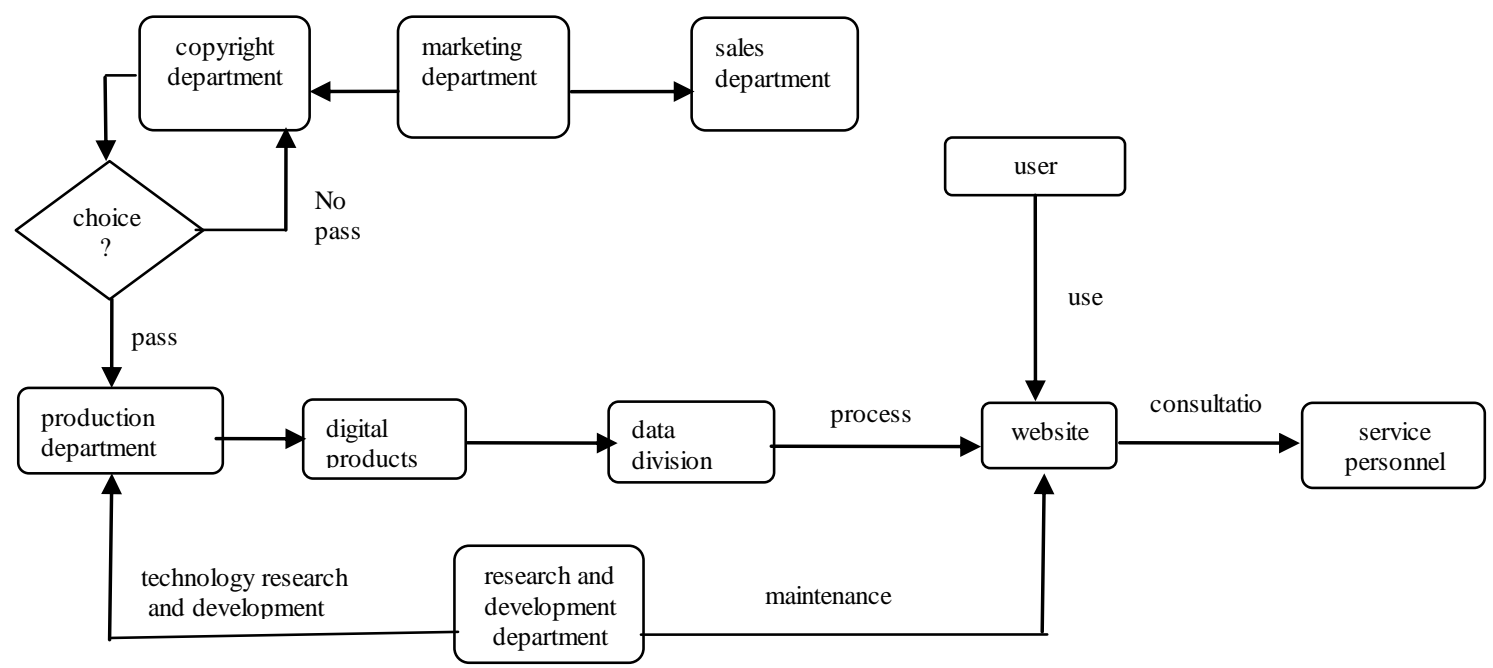

Figure 2. Cooperation relationship chart of departments

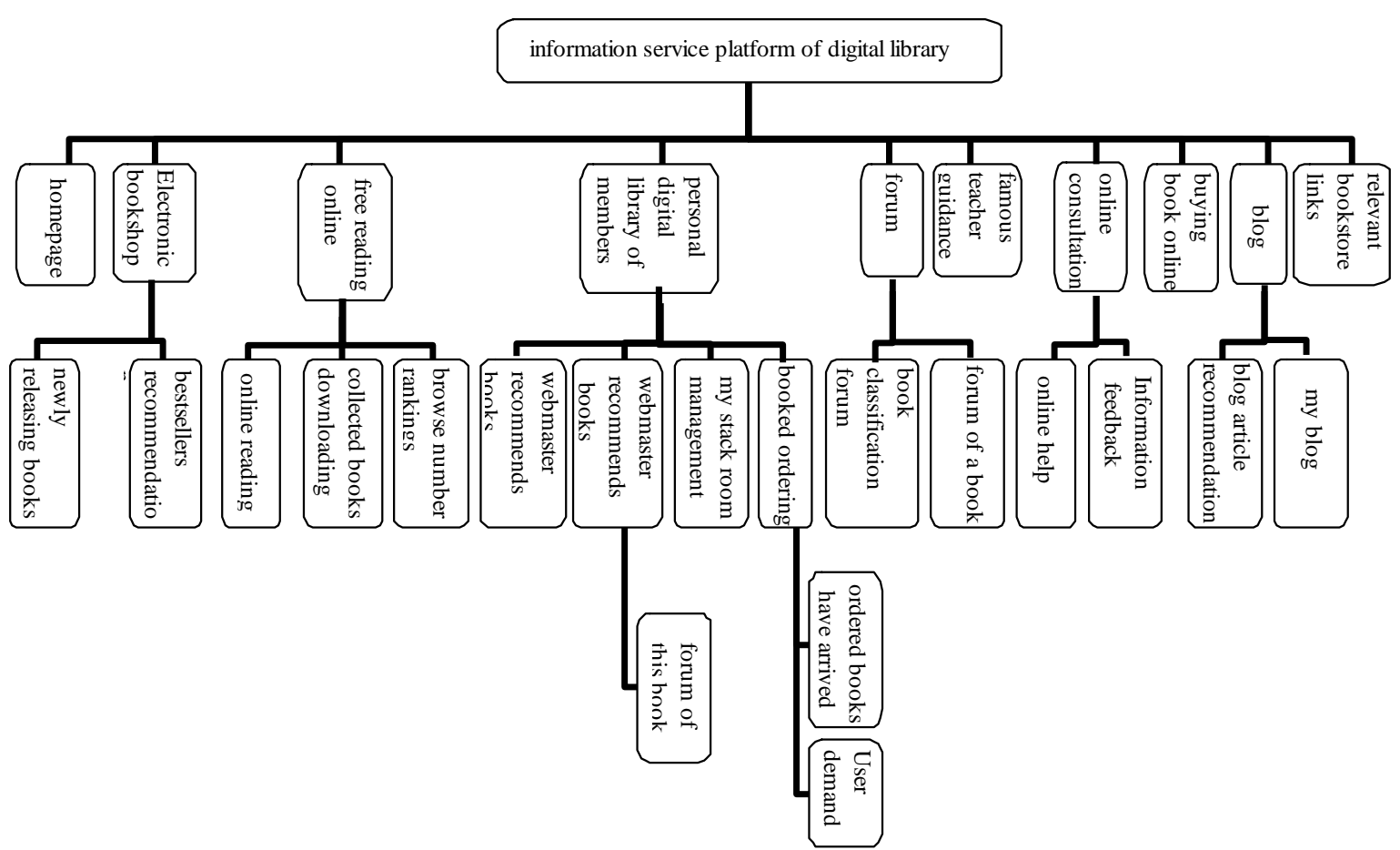

Figure 3. Information service platform structure of digital library

Construction of Perfect Information Service Platform. Digital library information service platform is a kind of information service platform that creates the information service environment 
which conforms to the personality demand for specific users and provides oriented scheduled information and service for users according to users' knowledge structure, information demand, behavior style, psychological tendency and so on. It uses the new technology and advanced business concept of digital library to engage in information resources content organization, digital processing, the total solution of digital library technology and application development of the construction of digital resources database. It provides professional, systematic and active multimedia information resources content services for the whole world [4-6] and helps users to establish personal information system [7].

Through the analysis of users demand and combined with the method of the enterprise operating of digital library, the information service platform which is shown in Fig . 3 is designed.

The design of the information service platform of digital library entirely depends on users' needs. They can not only communicate with each other in the forum, read online and manage personal digital libraries, but also provide their information to library through registering information. The administrator of the digital library can use these information to communicate with users in order to improve the quality of personalized service. This platform can reasonably divide users into different groups according to their age, educational level and the type of their favorite books. For users to find books, a perfect retrieval system should be established. This retrieval system should first make a good classification of books. Therefore, the library should not only consider the characteristics of lots of network information, complex content, quick change, poor stability, diversity, wide range, wide use, special network information organization and poor control, but also consider the characteristics and individual differences of network information users. Also it should have a sharp observation. It should know what users want earlier than the users themselves and provide them with pre service. It also should provide suitable personalized service model to users according to their different demands. At the same time, it should use the new technology and advanced business concept of digital library to engage in information resources content organization, digital processing, the total solution of digital library technology and application development of the construction of digital resources database. It provides professional, systematic and active multimedia information resources content services for the whole world [8]. "Providing the right information for the right users at the right time" has become the basic principle of information service.

\section{Adoption of the Core Business Model of Knowledge Capital Operation}

The key of enterprise operating of digital library is to do a good capital operation. Capital operation is a capital flow process of scientific management and management capital, which takes the capital flow as the premise and takes the increase of capital utility efficiency as the purpose. Firstly, capital flow is the precondition of capital operation. If the capital is not flowing, there will be no capital operation. Secondly, capital flow does not flow blindly, but flows to enterprises or departments with high capital efficiency and flows to areas where returns are high. Only by defining this goal can we do well in capital operation. Thirdly, capital operation should not only flow but also manage the management capital scientifically and combine capital flow with management effectively, so that capital operation can be carried out effectively.

In accordance with the general rules of enterprise capital operation, digital library implements capital operation. In addition to the overall reorganization of the digital library organization itself, assets and property rights in accordance with the laws of the market, the core content of it is knowledge capital operation. In the era of knowledge economy, knowledge is the most important resource and the most valuable asset of the enterprise. It is also an important capital for enterprise operation. "knowledge capital" refers to the knowledge that can be translated into market value, and it is the knowledge and skills that can bring profits for enterprises. The essence of knowledge capital is the total of the whole capital of the knowledge enterprise.

The operation of knowledge capital is the management of intangible assets. Specifically, intellectual capital refers to the brand, reputation, technology, intellectual property rights and so on. It no longer refers to tangible material assets and capital. Knowledge capital operation refers to how to arouse people's enthusiasm, give full play to human creativity and comprehensively use various spiritual 
resources to create spiritual products and knowledge products which can be accepted by society. Effective measures should be adopted to protect the intangible assets and intellectual property of enterprises and promote them to translate into the real wealth which can be measured by value. Digital library organization, assets and property rights restructuring are indirect capital operation. The reorganization of digital library organizations mainly solves the problem of irrational organization structure, which is the need of the development of market economy. Because the traditional library is a business organization which is based on the literature information collection, management and public welfare service. The funds which are invested by the state can not be added as capital in the process of operation.

In addition to the functions of traditional libraries, digital libraries also have the functions of information product development, production and management. Therefore, the digital libraries which are established on the basis of traditional libraries must meet the needs of the development of market economy. They should be recombined and transformed as the organization form and management model of enterprise operating. They should carry out institutional innovation, promote institutional change, carry out capital operation under the modern enterprise system and realize the purpose of capital increment of digital libraries through capital operation. The assets reorganization of the digital library is mainly to change the proportion of assets form and stock assets, adjust the combination structure of different assets and realize the transformation from assets to capital. The digital library of modern enterprise should get rid of this kind of management system, carry out system reform, establish corresponding enterprise operating mechanism, implement enterprise management, ensure the status of a legal person and define the property rights of the legal person. In that way, digital library can develop sustainably and steadily.

\section{Adoption of the Reasonable Marketing Strategy}

If the digital library wants to develop healthily and sustainably and achieves success, the system should be reformed, the operation mechanism should be changed, and the modern knowledge enterprise based on management knowledge information should be established. At the same time, the establishment of the capital operation in the central position of digital libraries and the development of capital operation are the fundamental solution for the sustainable development of digital library. The establishment of the right marketing form and strategy can make the digital library get certain economic benefits. Therefore, the digital library should make appropriate marketing strategy according to its development.

Pricing Strategy. Price is one of the important factors, which affects the choice of consumers and then it also affects the economic benefits of the enterprise operating of digital libraries. The library is a non-profit organization, but the purchase of a large amount of books and periodicals, the establishment of various information databases and the cost of education and training of administrators and books copyrights will spend lots of money. Therefore, the way of paying of relevant consumers who use digital library is the important link to apply to the digital library. In addition to the funds which are provided by government's financial department, digital library should assess carefully and then price the photocopy e-books, online downloads or online reading, information retrieval and other charge items to obtain certain cost effectiveness on the premise of taking the interests of consumers as the center.

Service Strategy. Firstly, all management staff should be required to understand the products in our website and know the characteristics of every product, so that management staff can answer all consumers' questions. A good quality of customer service can keep client base. Therefore, the library should be based on the concept of "user first" and combine its own collection features to provide high-quality brand services [9]. In that way, the digital library will be invincible in the complex enterprise marketing. During my internship, my manager said: "any department in our company should understand company's products and business concept, so that we can continue to improve the image of our company and understand what we are doing." Therefore, employees should always be strict with themselves and improve their quality.

Competition Strategy. Many important ideas in the field of strategic management come from the work of Michael Porter (Michael Porter) [10], whose competitive strategy illustrates the three general 
strategies that managers can use. Success depends on the matching of the chosen strategy and the competitive edge of the enterprise and the characteristics of the industry. When the digital library enterprise as an economic entity participates in the operation of market economy, it is inevitable to compete with other enterprises. The selection of competitive strategy depends on the success and failure of digital library enterprise to a great extent. The first strategy is the cost leadership strategy. It refers that the enterprise operating of digital library expands the scale of enterprise by increasing the speed and level of collecting information resources and the quality and efficiency of processing information resources to decrease the cost and defeat competitors in a low cost. The second strategy is the differentiation strategy. It refers that the digital library provides distinctive products to attract consumers to improve the market share. The third strategy is the focus strategy which is between the above two strategies. The purpose of it is to seek cost advantage (cost focus) or differentiation advantage (differentiation focus). I think the digital library can choose the focus strategy, because now the enterprise operating of the digital library is still in the primary stage, so it does not have the economic efficiency of scale or sufficient internal resources to successfully realize the other two strategies [11]. The digital library can introduce the digital products, information resources on the internet by using advertisement, online sales, public reporting, public relations and other ways of promotion. Also the digital library can understand the practical demand of users through the internet forum to perfect their own collection material, improve their competitiveness, develop their products and improve the service level [12].

Integration Strategy of the Technology. The characteristics of the diversification and systematization of the high and new technology which covers computer technology, communication technology, multimedia technology, internet technology and so on should be used fully to organize integrated innovation, form the core competitiveness of digital library enterprises, develop matching products and promote the development of related technology industries. Only by changing the management, marketing and service methods of traditional libraries and enhancing their own development and innovation ability, can they obtain the strong vitality of enterprise operating.

\section{Conclusion}

The development of the digital library is based on the enterprise operation of the digital library, the implementation of the full corporate management model and the operation mode of intellectual capital. We can find the service mode that users need according to the information service platform which is provided by the digital library, because the enterprise operating of the digital library is not only to improve economic efficiency and protect the copyright of authors and publishers, but also to meet the needs of users to improve the quality of service. In the era of information, knowledge will be the most important resource of an enterprise. Digital library has become the commanding height in the international high-tech competition and also become an important symbol to evaluate the construction of a national information infrastructure. Therefore, the encouragement and promotion of the development of the digital library enterprise have become the key point of the national economic policy. The enterprise operating mode of the digital library can promote the better development of it. The integration of the digital library with the market economy can not only improve the overall quality of people, but also promote the sustainable, steady and rapid increase of the national economy.

\section{Acknowledgements}

The authors wish to express their gratitude to the projects: "12th Five-Year" Education and Science Planning Subjects of Jilin Province (No. GH150208), "12th Five-Year” Social Science Research Planning Project and Innovation and entrepreneurship project of university students -- Construction of Micro-class teaching resource sharing platform in Jilin Agricultural University based on Mooc Concept for their generous support of this work. 


\section{References}

[1] L.Zhen: Journal of Xiangnan University, Vol.34 (2013), No.3, p.68. (In Chinese)

[2] S.Y.Yuan, X.E.Song and X.Y.Zhang: Journal of Daqing Normal University, Vol.14 (35), No.6, p.141. (In Chinese)

[3] W.H.Luan: Journal of Guiyang University, 2014, No.4, p.113. (In Chinese)

[4] X.Y.Wang: Library Research, 2014, No.2, p.35. (In Chinese)

[5] W.W.Yin: The Library Journal of Henan, Vol.37 (2017), No.3, p.106. (In Chinese)

[6] X.Liu, Y.H.Zhang, and D.X.Zhang, etc: Journal of Qingdao University, Vol.26 (2013), No.3, p.59. (In Chinese)

[7] L.W.Pan: Journal of Chifeng University, Vol.31 (2015), No.3, p.162. (In Chinese)

[8] P.Chen: Journal of Library and Information Science in Agriculture, Vol.28 (2016), No.4, p.88. (In Chinese)

[9] X.Chen: Industrial \& Science Tribune, Vol.15 (2016), No.24, p.272. (In Chinese)

[10] J.H.Wang: Journal of Modern Information, Vol.32 (2012), No.2, p.116. (In Chinese)

[11] X.B.Bai: Gansu Science and Technology, Vol.29 (2013), No.10, p.75. (In Chinese)

[12] L.Chen, Z.M.Cheng and H.Fang: Journal of Hunan City University, Vol.25 (2016), No.4, p.97. (In Chinese) 